\title{
Synthesis, characterization of N-, S-, O-substituted naphtho- and benzoquinones and a structural study
}

\author{
CEMIL IBIS* and NAHIDE GULSAH DENIZ \\ Engineering Faculty, Department of Chemistry, Division of Organic Chemistry, Istanbul University, \\ 34320, Avcilar Istanbul Turkey \\ e-mail: ibiscml@istanbul.edu.tr
}

MS received 2 May 2011; revised 22 November 2011; accepted 13 December 2011

\begin{abstract}
The new series of N-, S-, O-substituted 1,4-naphthoquinone and S-, O-substituted 1,4benzoquinone compounds were synthesized via vinylic substitution. Compounds $\mathbf{3}$ and $\mathbf{4}$ were synthesized from the reaction of $\mathbf{1}$ with $\mathbf{2}$. Compounds $\mathbf{6 , 7}$ and $\mathbf{8}$ were synthesized from reaction of $\mathbf{1}$ with $\mathbf{5}$. Compounds $\mathbf{1 0}$ and $\mathbf{1 1}$ were obtained from the reaction of $\mathbf{1}$ with $\mathbf{9}$. Compounds $\mathbf{1 3}$ and $\mathbf{1 4}$ were synthesized from the reaction of 1 with 12. Compounds 16 and $\mathbf{1 7}$ were obtained from the reaction of $\mathbf{1 5}$ with $\mathbf{2}$. Photochemical and electrochemical properties of $\mathrm{N}-, \mathrm{S}-, \mathrm{O}$-substituted quninone compounds were determined by using fluorescence spectroscopy and cyclic voltammetry. Crystal structure of 2-(7-sulphanyl-4-methyl-coumarinyl)-3-(1-ethoxy)1,4-naphthoquinone $\mathbf{1 3}$ was determined by X-ray diffraction method.
\end{abstract}

Keywords. 1,4-Naphthoquinone; $p$-chloranil; fluorescence spectroscopy; cyclic voltametry; $\mathrm{X}$-ray diffraction.

\section{Introduction}

Quinones are naturally occurring compounds with specific characteristics that have a great impact on the living cell. The ability to carry electrons makes them an important component of photosynthetic and respiratory electron transfer chain. ${ }^{1}$ They are considered as components of biological electron transfer chains located in the membranes of mitochondria, bacteria and chloroplasts. Quinones are good electron acceptors and are known to be efficient quenchers of singlet state donor fluorescence of various fluorophores. ${ }^{2}$ The current data are consistent with an electron transfer mechanism, ${ }^{3}$ and the quenching efficiency is dependent on the redox potentials of the corresponding quinone-hydroquinone system. From the perspectives of designing magnetic materials ${ }^{4}$ and understanding photo-physical properties, ${ }^{5}$ the co-ordination chemistry of quinones is also very important. The quinones also find application as electrode material. ${ }^{6}$

Depending on the molecular structure, some quinones can be used as vitamin sor drugs. ${ }^{7}$ It is recognized that the quinone nucleus and the substituents are both essential to develop specific biochemical functions. So, when the quinonic ring is substituted by an appropriate alkylchain, these compounds can exhibit

*For correspondence anticancer and antitumour activity. ${ }^{8}$ Naphthoquinone derivatives are an important class of naturally occurring compounds as they have favourable antimicrobial, antiparasitic, and phytotoxic activities. ${ }^{9,10}$ The biological activity of quinones results from their ability to accept one or two electrons to form the corresponding radical anion or dianion species, and also their acidbase properties. Electron-attracting or -donating substituents modulate the redox properties of quinones, i.e., their variable ability to accept electrons. The molecular basis of quinone toxicity is the enzyme-catalysed reduction to semiquinone radicals, which then reduce oxygen to superoxide anion radicals thereby regenerating the quinone. ${ }^{11}$ Further need for a study of the aryl amino-1,4-naphthoquinones is illustrated by the observation that the ortho-amino quinoid unit is present in many antitumour antibiotics such as actinomycins, mitomycin $\mathrm{C}$, porfiromycin, and streptonigrin. ${ }^{12}$

It has been reported that some $\mathrm{N}-, \mathrm{S}-$, $\mathrm{O}$-subsituted naphtho- and benzoquinone compounds were synthesized from 2,3-dichloro-1,4-naphthoquinone or $p$ chloranil. ${ }^{13-15}$ In an earlier study by Prescott et al. the antitumour activity of 2,2-Hydrazobis(3-chloro-1,4naphthoquinone) were investigated. ${ }^{16}$ Novel vitamin $\mathrm{K}_{3}$ analogues were synthesized and evaluated for their anticancer activity by Chen et al. ${ }^{17} \mathrm{~N}$-substituted enaminones were synthesized from 1,4-naphthoquinones by Parr et al. ${ }^{18} \mathrm{We}$ describe here the synthesis of some naphtho- 
and benzoquinone compounds and characterization of their structures by using micro analysis, FT-IR, ${ }^{1} \mathrm{H}-\mathrm{NMR},{ }^{13} \mathrm{C}-\mathrm{NMR}, \mathrm{MS}$, UV-Vis. Photo- and electrochemical properties of N-, S-, O-substituted naphthoand benzoquinone compounds were investigated by using fluorescence spectroscopy and cyclic voltammetry method. The single crystal structure of compound 13 was determined by X-ray diffraction method.

\section{Experimental}

\subsection{General}

Melting points were measured on a Buchi B-540 melting point apparatus. Elemental analyses were performed on a Thermo Finnigan Flash EA 1112 Elemental analyser. Infrared (IR) spectra were recorded in $\mathrm{KBr}$ pellets in Nujol mulls on a Perkin Elmer Precisely Spectrum One FTIR spectrometry. UV spectra in $\mathrm{CHCl}_{3}$, THF and MetOH were recorded on Perkin Elmer Lambda 35 UV/VIS Spectrometer. ${ }^{1} \mathrm{H}$ and ${ }^{13} \mathrm{C}$ NMR spectra were recorded on VarianUNITYINOVA operating at $500 \mathrm{MHz}$. Mass spectra were obtained on a Thermo Finnigan LCQ Advantage MAX LC/MS/MS spectrometer according to ESI probe. Products were isolated by column chromatography on Silica gel (Fluka Silica gel 60, particle size 63-200 $\mu \mathrm{m}$ ). TLC plates silica $60 \mathrm{~F}_{254}$ (Merck, Darmstadt), detection with ultraviolet light $(254 \mathrm{~nm})$. All chemicals were reagent grade and used without further purification. Moisture was excluded from the glass apparatus using $\mathrm{CaCl}_{2}$ drying tubes. Solvents, unless otherwise specified, were of reagent grade and distilled once prior to use.

\subsection{Fluorescence measurements}

Fluorescence spectra were run on a VARIAN Cary Eclipse Fluorescence Spectrophotometer. Excitation and emission spectra were measured for $10^{-4} \mathrm{M}$ solutions for all compounds in $\mathrm{MetOH} / \mathrm{CHCl}_{3}(1: 1)$ at room temperature. Excitation and emission slit widths were set at $10 \mathrm{~nm}$.

\subsection{Crystal structure determination and refinement}

Red crystals of compound suitable for X-ray diffraction analysis were obtained by slow evaporation of an ethylacetate solution at room temperature. A red crystal of compound $13, \mathrm{C}_{22} \mathrm{H}_{16} \mathrm{O}_{5} \mathrm{~S}_{1}$, having approximate dimensions of $0.50 \times 0.30 \times 0.10 \mathrm{~mm}$ was mounted on a glass fibre. All measurements were made on a Rigaku R-Axis Rapid-S imaging plate area detector with graphite monochromated Mo-K $\alpha$ radiation $(\lambda=0.71073 \AA)$. The data were collected at room temperature to a maximum $2 \theta$ value of $60.3^{\circ}$. Experimental conditions were summarized in table 1 . The structure was solved

Table 1. Crystal data and refinement parameters for compound $\mathbf{1 3 .}$

\begin{tabular}{|c|c|}
\hline CCDC deposit number & CCDC 724897 \\
\hline Empirical formula & $\mathrm{C}_{22} \mathrm{H}_{16} \mathrm{O}_{5} \mathrm{~S}$ \\
\hline Crystal colour, habit & Red, block \\
\hline Formula weight & 392.43 \\
\hline Temperature & 293(2) K \\
\hline Wavelength & $0.71073 \AA$ \\
\hline Crystal system & Triclinic \\
\hline Space group & $\mathrm{P}-1$ \\
\hline Cell dimensions & $\begin{array}{c}\mathrm{a}=8.4474(2) \AA, \mathrm{b}=9.1257(1) \AA \\
\mathrm{c}=11.9197(2) \AA, \alpha=84.474(4)^{\circ} \\
\beta=84.506(4)^{\circ}, \gamma=80.473(4)^{\circ}\end{array}$ \\
\hline Volume & $899.00(3) \AA^{3}$ \\
\hline $\mathrm{Z}$ & 2 \\
\hline Density (calculated) & $1.450 \mathrm{mg} / \mathrm{m}^{3}$ \\
\hline Absorption coefficient & $0.213 \mathrm{~mm}^{-1}$ \\
\hline$F_{000}$ & 408.00 \\
\hline Index ranges & $\begin{array}{c}-10 \leq \mathrm{h} \leq 11,-12 \leq \mathrm{k} \leq 12 \\
-16 \leq 1 \leq 16\end{array}$ \\
\hline Reflections collected & $7 \overline{1430}$ \\
\hline Independent reflections & $5254\left[\mathrm{R}_{\mathrm{int}}=0.042\right]$ \\
\hline Data/restraints/parameters & $4958 / 0 / 253$ \\
\hline Goodness of fit indicator & 1.095 \\
\hline Final R indices $[I>2 \sigma(\mathrm{I})]$ & $\mathrm{R}_{1}=0.056, \mathrm{wR}_{2}=0.098$ \\
\hline Largest diff. peak and hole & 0.47 and -0.46 e. $\AA^{-3}$ \\
\hline
\end{tabular}


by SIR $92^{19}$ and refined with CRYSTALS. ${ }^{20}$ The non-hydrogen atoms were refined anisotropically. $\mathrm{H}$ atoms were located in geometrically idealized positions $\mathrm{C}-\mathrm{H}=0.95(6) \AA$ and treated as riding and $U_{\text {iso }}(\mathrm{H})=$ $1.2 U_{\mathrm{eq}}(\mathrm{C})$. The selected bond distances, bond and torsion angles for compound $\mathbf{1 3}$ were listed in tables 2 and 3, respectively. Drawings were performed with the program ORTEP-III ${ }^{21}$ with $50 \%$ probability displacement elipsoide for compound $\mathbf{1 3}$ in figure 1. Crystallographic data (excluding structure factors) for the structure reported in this paper have been deposited with the Cambridge Crystallographic Data Centre as supplementary publication no. CCDC-724897 for $\mathbf{1 3} .^{22}$

\subsection{Cyclic voltammetry measurements}

Electrochemical cyclic voltammetry measurements were performed at room temperature in an airtight three-electrode cell by using a glassy carbon electrode (GCE) with a $0.071 \mathrm{~cm}^{2}$ surface area as the working electrode, a platinum wire served as the counter electrode and a $\mathrm{Ag} / \mathrm{AgCl}$ (in a saturated $\mathrm{KCl}$ solution) reference electrode. The cell was driven with a computer controlled system of a Gamry Reference 600 Model potentiostat/galvanostat. The solutions were deoxygenated by bubbling nitrogen through them for approximately $5 \mathrm{~min}$. The surface of the working electrode was polished with deagglomerated alumina (a particle size of 0.05 micron) before each run. The electrochemical reaction vessel was charged with $10 \mathrm{~mL}$ an DMF solution of $1,3,4,6,7,8,10,11,13,14,15$, 16 and $17\left(1 \times 10^{-4} \mathrm{M}\right)$ and tetrabutyl ammonium perchlorate $(0.1 \mathrm{M})$ as the electrolyte. Measurements were made over a potential range between 0 and $-2 \mathrm{~V}$ for $\mathbf{1}, \mathbf{3}, \mathbf{4}, \mathbf{6}, \mathbf{8}, \mathbf{1 0}, \mathbf{1 1}, \mathbf{1 5},+1.0$ and $-2.5 \mathrm{~V}$ for 7,0 and $-2.5 \mathrm{~V}$ for 13,0 and $-1.8 \mathrm{~V}$ for $14,16,17$ with a scan rate of $0.1 \mathrm{~V} \mathrm{~s}^{-1}$. Voltammetric parameters for all compounds are summarized in table 6 .

\subsection{Synthesis procedures}

Method 1: Sodium carbonate (1.52 g) was dissolved $(60 \mathrm{~mL})$ in ethanol. 2,3-dichloro-1,4-naphthoquinone or

Table 2. Selected bond distances ( $\AA$ ) for compound 13.

\begin{tabular}{lccc}
\hline Atom & Distance & Atom & Distance \\
\hline C1-C2 & $1.354(2)$ & C3-O2 & $1.212(2)$ \\
C2-C3 & $1.495(3)$ & C10-O1 & $1.220(2)$ \\
C1-S1 & $1.762(2)$ & C2-O3 & $1.338(3)$ \\
C11-S1 & $1.765(2)$ & C18-O5 & $1.209(3)$ \\
C15-C16 & $1.509(3)$ & C18-O4 & $1.376(2)$ \\
C21-C22 & $1.505(4)$ & C19-O4 & $1.375(2)$ \\
\hline
\end{tabular}

Table 3. Selected bond and torsion angles $\left({ }^{\circ}\right)$ for compound 13.

\begin{tabular}{lccr}
\hline Atom & $\begin{array}{c}\text { Bond } \\
\text { angle }\end{array}$ & Atom & \multicolumn{1}{c}{$\begin{array}{c}\text { Torsion } \\
\text { angle }\end{array}$} \\
\hline C1-C2-C3 & $121.4(2)$ & C3-C2-C1-C10 & $-5.7(3)$ \\
C2-C3-C4 & $117.1(1)$ & O1-C10-C1-C2 & $-176.1(2)$ \\
C2-C3-O2 & $121.2(2)$ & O2-C3-C2-O3 & $3.2(3)$ \\
C1-C10-O1 & $120.8(2)$ & C10-C1-S1-C11 & $134.4(1)$ \\
S1-C1-C10 & $115.3(1)$ & C15-C17-C18-O5 & $173.3(2)$ \\
C1-S1-C11 & $104.0(8)$ & C18-O4-C19-C20 & $176.5(1)$ \\
C18-O4-C19 & $121.7(2)$ & C15-17-C18-O4 & $-5.3(3)$ \\
O4-C18-O5 & $116.6(2)$ & C11-S1-C1-C2 & $-49.4(2)$ \\
C2-O3-C21 & $124.5(2)$ & C1-C2-C3-O2 & $-171.3(2)$ \\
\hline
\end{tabular}

p-chloranil and nucleophile compounds were added slowly to this solution for synthesis of compounds $\mathbf{3}$, $4,6,7,8,10,11,16$ and 17. Without heating, the mixture was stirred for $24 \mathrm{~h}$. In addition, 2,3-dichloro-1,4naphthoquinone and thiols were stirred for $12 \mathrm{~h}$ in a mixture solution of ethanol $(25 \mathrm{~mL})$ with triethlyamine $(1 \mathrm{~mL})$ for the synthesis of compounds $\mathbf{1 3}$ and $\mathbf{1 4}$. The colour of the solution quickly changed and the extent of the reaction was monitored by TLC. Chloroform $(30 \mathrm{~mL})$ was added to the reaction mixture. The organic layer was washed with water $(4 \times 30 \mathrm{~mL})$, and dried with $\mathrm{Na}_{2} \mathrm{SO}_{4}$. After the solvent was evaporated the residue was purified by column chromatography on silica gel (scheme 1).

2.5a 2-(11-Sulphanyl-1-undecanol)-3-ethoxy-1,4naphthoquinone (3): Compound $\mathbf{3}$ was synthesized from the reaction of $\mathbf{1}(1 \mathrm{~g}, 4.4 \mathrm{mmol})$ with $\mathbf{2}(0.9 \mathrm{~g}$, $4.4 \mathrm{mmol}$ ) according to method 1. Red oil, Yield: $0.6 \mathrm{~g}(34 \%) . \mathrm{R}_{f}: 0.50\left[\mathrm{CH}_{2} \mathrm{Cl}_{2} / \mathrm{EtAc}(4: 1)\right]$. IR $(\mathrm{KBr}$ pellet, $\left.\mathrm{cm}^{-1}\right): 3410(\mathrm{OH}), 3070(\mathrm{Ar}-\mathrm{H}), 2925,2851$ $(\mathrm{C}-\mathrm{H}), 1661(\mathrm{C}=\mathrm{O}), 1591,1543(\mathrm{C}=\mathrm{C}) .{ }^{1} \mathrm{H}$ NMR $\left(499.74 \mathrm{MHz}, \mathrm{CDCl}_{3}\right): \delta=1.2(\mathrm{t}, J=6.84 \mathrm{~Hz}, 3 \mathrm{H}$, $\left.\mathrm{CH}_{3}\right), 1.3-1.4\left(\mathrm{~m}, 14 \mathrm{H}, \mathrm{CH}_{2}\right), 1.45-1.6\left(\mathrm{~m}, 2 \mathrm{H}, \mathrm{S}_{-} \mathrm{CH}_{2}-\right.$ $\left.\mathrm{CH}_{2}\right), 1.7\left(\mathrm{~m}, 2 \mathrm{H}, \mathrm{CH}_{2}-\mathrm{CH}_{2}-\mathrm{OH}\right), 3.1$ (t, $J=7.32 \mathrm{~Hz}$, $\left.2 \mathrm{H}, \mathrm{S}-\mathrm{CH}_{2}\right), 3.6\left(\mathrm{t}, J=6.83 \mathrm{~Hz}, 2 \mathrm{H}, \mathrm{CH}_{2}-\mathrm{OH}\right), 3.7$ $(\mathrm{s}, 1 \mathrm{H}, \mathrm{OH}), 4.4\left(\mathrm{q}, 2 \mathrm{H}, \mathrm{O}-\mathrm{CH}_{2}\right), 7.60(\mathrm{t}, J=6.34 \mathrm{~Hz}$, $\left.1 \mathrm{H}, \mathrm{H}_{\text {arom }}\right), 7.65\left(\mathrm{t}, J=5.37 \mathrm{~Hz}, 1 \mathrm{H}, \mathrm{H}_{\text {arom }}\right), 7.95$ (dd, $J=6.34 \mathrm{~Hz}, J=6.83 \mathrm{~Hz}, 1 \mathrm{H}, \mathrm{H}_{\text {arom }}$ ), $8.05 \mathrm{ppm}$ $\left(\mathrm{dd}, J=5.37 \mathrm{~Hz}, J=5.37 \mathrm{~Hz}, 1 \mathrm{H}, \mathrm{H}_{\text {arom }}\right) .{ }^{13} \mathrm{C} \mathrm{NMR}$ $\left(125.66 \mathrm{MHz}, \mathrm{CDCl}_{3}\right): \delta=14.89\left(\mathrm{CH}_{3}\right), 24.73,27.60$, 27.67, 28.04, 28.10, 28.38, $28.40\left(\mathrm{CH}_{2}\right), 28.52$ (S$\left.\mathrm{CH}_{2}-\mathrm{CH}_{2}\right), 29.41\left(\mathrm{CH}_{2}-\mathrm{CH}_{2}-\mathrm{OH}\right), 33.33\left(\mathrm{~S}_{-} \mathrm{CH}_{2}\right)$, $61.97\left(\mathrm{CH}_{2}-\mathrm{OH}\right), 68.88\left(\mathrm{O}-\mathrm{CH}_{2}\right), 125.35,125.56$, $132.49,132.54\left(\mathrm{CH}_{\text {arom }}\right), 126.16,132.75\left(\mathrm{C}_{\text {arom }}\right)$, 133.07 (=C-S), 156.75 (=C-O), 178.85, $181.85 \mathrm{ppm}$ $(\mathrm{C}=\mathrm{O}) . \mathrm{MS}[+\mathrm{ESI}]: \mathrm{m} / \mathrm{z} 405[\mathrm{M}]^{+}, 359[\mathrm{M}-45]^{+}$. Anal. Calcd. for $\mathrm{C}_{23} \mathrm{H}_{32} \mathrm{O}_{4} \mathrm{~S}_{1}$ (M, 404.57): C, 68.28; H, 7.97; S, 7.92. Found: C, 68.30; H, 6.88; S, 7.98. 


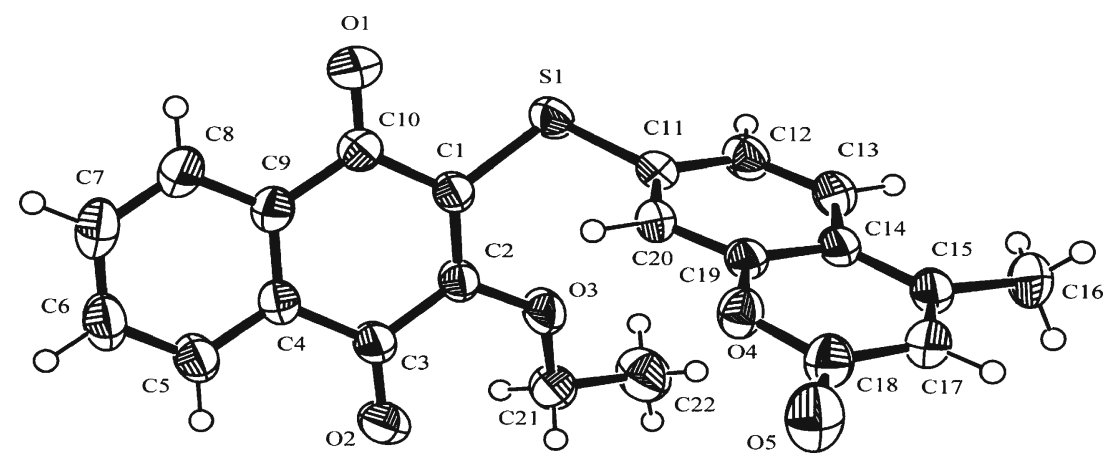

Figure 1. The crystal structure of 13. Displacement ellipsoids are plotted at the $50 \%$ probability level (symmetry transformations used to generate equivalent atoms: (i)- $\mathrm{x},-\mathrm{y},-\mathrm{z}$ ).

2.5b 2,3-Bis(11-sulphanyl-1-undecanol)-1,4-naphthoquinone (4): Compound 4 was synthesized from the reaction of $1(1 \mathrm{~g}, 4.4 \mathrm{mmol})$ with $2(0.9 \mathrm{~g}, 4.4 \mathrm{mmol})$ according to method 1 . Orange solid. M.p.: $76-77^{\circ} \mathrm{C}$. Yield: $1.3 \mathrm{~g}(53 \%) . \mathrm{R}_{f}: 0.32\left[\mathrm{CH}_{2} \mathrm{Cl}_{2} / \mathrm{EtAc}(4: 1)\right]$. IR $(\mathrm{KBr}$ pellet, $\left.\mathrm{cm}^{-1}\right): 3314(\mathrm{OH}), 3062(\mathrm{Ar}-\mathrm{H}), 2913,2847$ (C-H), $1665(\mathrm{C}=\mathrm{O}), 1588,1512(\mathrm{C}=\mathrm{C}) .{ }^{1} \mathrm{H}$ NMR $\left(499.74 \mathrm{MHz}, \mathrm{CDCl}_{3}\right): \delta=1.1-1.3\left(\mathrm{~m}, 28 \mathrm{H}, \mathrm{CH}_{2}\right)$, 1.3-1.4 (m, 4H, S- $\left.\mathrm{CH}_{2}-\mathrm{CH}_{2}\right), 1.5-1.6\left(\mathrm{~m}, 4 \mathrm{H}, \mathrm{CH}_{2}-\right.$ $\left.\mathrm{CH}_{2}-\mathrm{OH}\right), 3.2\left(\mathrm{t}, J=7.32 \mathrm{~Hz}, 4 \mathrm{H}, \mathrm{S}-\mathrm{CH}_{2}\right), 3.6(\mathrm{t}$, $\left.J=6.35 \mathrm{~Hz}, 4 \mathrm{H}, \mathrm{CH}_{2}-\mathrm{OH}\right), 3.8(\mathrm{~s}, 2 \mathrm{H}, \mathrm{OH}), 7.60$ $\left(\mathrm{dd}, J=5.86 \mathrm{~Hz}, J=5.85 \mathrm{~Hz}, 2 \mathrm{H}, \mathrm{H}_{\text {arom }}\right), 7.97 \mathrm{ppm}$ $\left(\mathrm{dd}, J=5.36 \mathrm{~Hz}, J=5.86 \mathrm{~Hz}, 2 \mathrm{H}, \mathrm{H}_{\text {arom }}\right) .{ }^{13} \mathrm{C} \mathrm{NMR}$ $\left(125.66 \mathrm{MHz}, \mathrm{CDCl}_{3}\right): \delta=24.74,27.69,28.10,28.39$, 28.43, 28.46, $28.54\left(\mathrm{CH}_{2}\right), 29.44\left(\mathrm{~S}-\mathrm{CH}_{2}-\mathrm{CH}_{2}\right), 31.79$
$\left(\mathrm{CH}_{2}-\mathrm{CH}_{2}-\mathrm{OH}\right), 33.96\left(\mathrm{~S}-\mathrm{CH}_{2}\right), 62.01 \quad\left(\mathrm{CH}_{2}-\mathrm{OH}\right)$, $125.82,132.38\left(\mathrm{CH}_{\text {arom }}\right), 132.06\left(\mathrm{C}_{\text {arom }}\right), 146.89$ (=C$\mathrm{S}), 178.01 \mathrm{ppm}(\mathrm{C}=\mathrm{O}) . \mathrm{MS}[+\mathrm{ESI}]: \mathrm{m} / \mathrm{z} 563[\mathrm{M}]^{+}, 546$ $[\mathrm{M}-17]^{+}$. Anal. Calcd. for $\mathrm{C}_{32} \mathrm{H}_{50} \mathrm{O}_{4} \mathrm{~S}_{2}(\mathrm{M}, 562.88)$ : C, 68.28; H, 8.95; S, 11.39. Found: C, 68.40; H, 9.08; S, 11.28 .

2.5c [2,3-Cyclo-(2-butylamino)ethanesulphanyl]-1,4naphthoquinone (6): Compound $\mathbf{6}$ was synthesized from the reaction of $\mathbf{1}(1 \mathrm{~g}, 4.4 \mathrm{mmol})$ with $\mathbf{5}(0.58 \mathrm{~g}$, $4.4 \mathrm{mmol}$ ) according to method 1. Purple solid. M.p.: $125-126^{\circ} \mathrm{C}$. Yield: $0.4 \mathrm{~g}(31 \%) . \mathrm{R}_{f}: 0.60\left(\mathrm{CH}_{2} \mathrm{Cl}_{2}\right)$. IR $\left(\mathrm{KBr}\right.$ pellet, $\left.\mathrm{cm}^{-1}\right)$ : 3069 (Ar-H), 2955, 2928, 2860 (C$\mathrm{H}), 1657,1624(\mathrm{C}=\mathrm{O}), 1587,1532(\mathrm{C}=\mathrm{C}) .{ }^{1} \mathrm{H}$ NMR

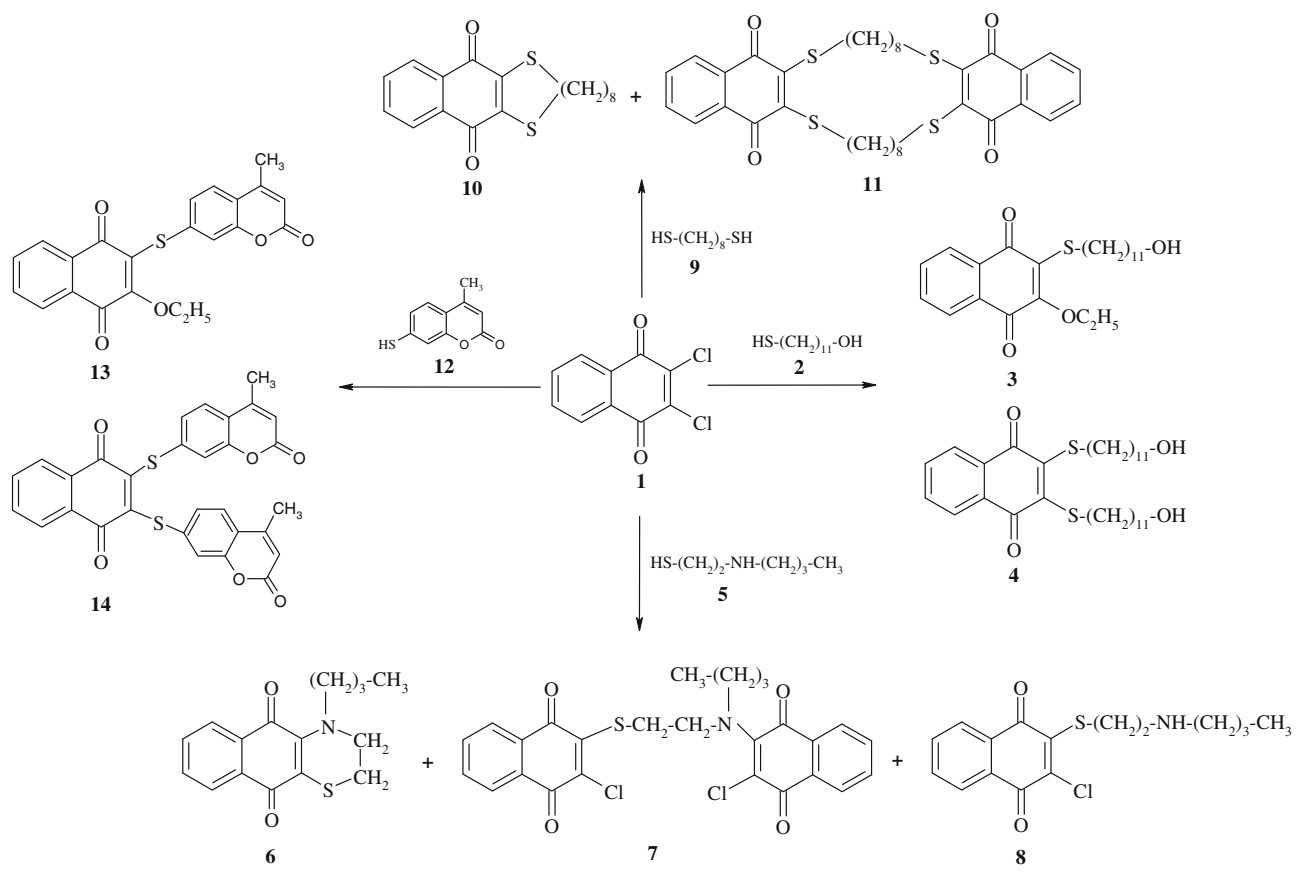

Scheme 1. Synthesis of compounds $3,4,6,7,8,10,11,13$ and 14 . 
$\left(499.74 \mathrm{MHz}, \mathrm{CDCl}_{3}\right): \delta=0.8(\mathrm{t}, J=7.32 \mathrm{~Hz}, 3 \mathrm{H}$, $\left.\mathrm{CH}_{3}\right), 1.2-1.4\left(\mathrm{~m}, 2 \mathrm{H}, \mathrm{CH}_{2}\right), 1.6-1.7\left(\mathrm{~m}, 2 \mathrm{H}, \mathrm{N}_{-} \mathrm{CH}_{2-}\right.$ $\left.\mathrm{CH}_{2}\right), 2.9\left(\mathrm{t}, \mathrm{J}=6.81 \mathrm{~Hz}, 2 \mathrm{H}, \mathrm{N}-\mathrm{CH}_{2}-\mathrm{CH}_{2}\right), 3.3(\mathrm{t}, \mathrm{J}=$ $\left.7.81 \mathrm{~Hz}, 2 \mathrm{H}, \mathrm{S}-\mathrm{CH}_{2}\right), 3.5\left(\mathrm{t}, J=6.84 \mathrm{~Hz}, 2 \mathrm{H}, \mathrm{N}-\mathrm{CH}_{2}\right)$, $7.50\left(\mathrm{t}, J=7.32 \mathrm{~Hz}, 1 \mathrm{H}, \mathrm{H}_{\text {arom }}\right), 7.55(\mathrm{t}, J=7.81 \mathrm{~Hz}$, $\left.1 \mathrm{H}, \mathrm{H}_{\text {arom }}\right), 7.85(\mathrm{dd}, J=6.84 \mathrm{~Hz}, J=6.85 \mathrm{~Hz}, 1 \mathrm{H}$, $\left.\mathrm{H}_{\text {arom }}\right), 7.95 \mathrm{ppm}(\mathrm{dd}, J=7.32 \mathrm{~Hz}, J=6.84 \mathrm{~Hz}, 1 \mathrm{H}$, $\left.\mathrm{H}_{\text {arom }}\right) .{ }^{13} \mathrm{C}$ NMR $\left(125.66 \mathrm{MHz}, \mathrm{CDCl}_{3}\right): \delta=12.89$ $\left(\mathrm{CH}_{3}\right), 19.08\left(\mathrm{CH}_{2}\right), 23.45\left(\mathrm{~N}-\mathrm{CH}_{2}-\mathrm{CH}_{2}\right), 30.28$ (S$\left.\mathrm{CH}_{2}\right), 49.17\left(\mathrm{~N}-\mathrm{CH}_{2}-\mathrm{CH}_{2}\right), 54.22\left(\mathrm{~N}^{-} \mathrm{CH}_{2}\right), 120.38$, $124.57,125.52,131.18,131.30,131.56\left(\mathrm{CH}_{\text {arom }}, \mathrm{C}_{\text {arom }}\right)$, 132.26 (=C-S), 145.13 (=C-N), 176.80, $178.82 \mathrm{ppm}$ $(\mathrm{C}=\mathrm{O}) . \mathrm{MS}[+\mathrm{ESI}]: \mathrm{m} / \mathrm{z} 288[\mathrm{M}]^{+}, 232[\mathrm{M}-56]^{+}$. Anal. Calcd. for $\mathrm{C}_{16} \mathrm{H}_{17} \mathrm{O}_{2} \mathrm{~S}_{1} \mathrm{~N}_{1}$ (M, 287.38): C, 66.87; H, 5.96; N, 4.87; S, 11.15. Found: C, 64.40; H, 5.88; $\mathrm{N}, 4.85 ; \mathrm{S}, 11.18$.

2.5d [2-(Butylamino)ethanesulphanyl][2,2']-dichloro[3, 3']-bis(1,4-naphthoquinone) (7): Compound 7 was synthesized from the reaction of $\mathbf{1}(1 \mathrm{~g}, 4.4 \mathrm{mmol})$ with $5(0.58 \mathrm{~g}, 4.4 \mathrm{mmol})$ according to method 1 . Black solid. M.p.: $97-98^{\circ} \mathrm{C}$. Yield: $1.1 \mathrm{~g}(48 \%) . \mathrm{R}_{f}$ : 0.40 (EtAc). IR ( $\mathrm{KBr}$ pellet, $\left.\mathrm{cm}^{-1}\right): 3069$ (Ar-H), 2957, 2928, $2871(\mathrm{C}-\mathrm{H}), 1662(\mathrm{C}=\mathrm{O}), 1592,1556$ $(\mathrm{C}=\mathrm{C}) .{ }^{1} \mathrm{H}$ NMR $\left(499.74 \mathrm{MHz}, \mathrm{CDCl}_{3}\right): \delta=0.9(\mathrm{t}$, $\left.J=7.32 \mathrm{~Hz}, 3 \mathrm{H}, \mathrm{CH}_{3}\right), 1.1-1.4\left(\mathrm{~m}, 2 \mathrm{H}, \mathrm{CH}_{2}\right), 1.6-$ $1.7\left(\mathrm{~m}, 2 \mathrm{H}, \mathrm{N}-\mathrm{CH}_{2}-\mathrm{CH}_{2}\right), 3.0(\mathrm{t}, J=6.81 \mathrm{~Hz}, 2 \mathrm{H}$, $\left.\mathrm{N}-\mathrm{CH}_{2}-\mathrm{CH}_{2}\right), 3.8\left(\mathrm{t}, \mathrm{J}=7.32 \mathrm{~Hz}, 2 \mathrm{H}, \mathrm{S}-\mathrm{CH}_{2}\right), 4.1$ $\left(\mathrm{t}, J=6.84 \mathrm{~Hz}, 2 \mathrm{H}, \mathrm{N}-\mathrm{CH}_{2}\right), 7.50(\mathrm{t}, J=5.84 \mathrm{~Hz}$, $\left.1 \mathrm{H}, \mathrm{H}_{\text {arom }}\right), 7.65\left(\mathrm{t}, J=6.83 \mathrm{~Hz}, 1 \mathrm{H}, \mathrm{H}_{\text {arom }}\right), 7.95$ (dd, $\left.J=5.32 \mathrm{~Hz}, J=5.85 \mathrm{~Hz}, 1 \mathrm{H}, \mathrm{H}_{\text {arom }}\right), 8.10 \mathrm{ppm}$ (dd, $\left.J=5.32 \mathrm{~Hz}, J=5.84 \mathrm{~Hz}, 1 \mathrm{H}, \mathrm{H}_{\text {arom }}\right) .{ }^{13} \mathrm{C} \mathrm{NMR}$ $\left(125.66 \mathrm{MHz}, \mathrm{CDCl}_{3}\right): \delta=12.70\left(\mathrm{CH}_{3}\right), 18.81\left(\mathrm{CH}_{2}\right)$, $22.78\left(\mathrm{~N}^{\left.-\mathrm{CH}_{2}-\mathrm{CH}_{2}\right), 29.39\left(\mathrm{~S}-\mathrm{CH}_{2}\right), 43.72\left(\mathrm{~N}-\mathrm{CH}_{2}-\right.}\right.$ $\left.\mathrm{CH}_{2}\right), 67.18\left(\mathrm{~N}-\mathrm{CH}_{2}\right), 125.77,125.84,127.80,131.33$, 131.51, $131.87\left(\mathrm{CH}_{\text {arom, }} \mathrm{C}_{\text {arom }}\right), 133.90$ (=C-S), 143.29 $(=\mathrm{C}-\mathrm{Cl}), 148.89$ (=C-N), 179.60, $183.43 \mathrm{ppm}(\mathrm{C}=\mathrm{O})$. MS[+ESI]: m/z $478[\mathrm{M}-37]^{+}, 441[\mathrm{M}-73]^{+}$. Anal. Calcd. for $\mathrm{C}_{26} \mathrm{H}_{21} \mathrm{O}_{4} \mathrm{~S}_{2} \mathrm{~N}_{1} \mathrm{Cl}_{2}$ (M, 514.43): C, 60.70; $\mathrm{H}$, 4.11; N, 2.72; S, 12.46 Found: C, 60.68; H, 4.08; N, 2.65, S, 12.28 .

2.5e 2-[2-(Butylamino)ethanesulphanyl]-3-chloro-1, 4-naphthoquinone $(\mathbf{8})$ : Compound $\mathbf{8}$ was synthesized from the reaction of $\mathbf{1}(1 \mathrm{~g}, 4.4 \mathrm{mmol})$ with $\mathbf{5}(0.58 \mathrm{~g}$, $4.4 \mathrm{mmol}$ ) according to method 1. Black solid. M.p.: 110-111 ${ }^{\circ} \mathrm{C}$. Yield: $0.3 \mathrm{~g}(21 \%) . \mathrm{R}_{f}$ : $0.45\left(\mathrm{CH}_{2} \mathrm{Cl}_{2}\right)$. IR $\left(\mathrm{KBr}\right.$ pellet, $\left.\mathrm{cm}^{-1}\right): 3344(\mathrm{NH}), 3068(\mathrm{Ar}-\mathrm{H})$, 2956, 2929, $2870(\mathrm{C}-\mathrm{H}), 1659(\mathrm{C}=\mathrm{O}), 1591,1557$ $(\mathrm{C}=\mathrm{C}) .{ }^{1} \mathrm{H}$ NMR $\left(499.74 \mathrm{MHz}, \mathrm{CDCl}_{3}\right): \delta=0.8(\mathrm{t}$, $\left.J=7.32 \mathrm{~Hz}, 3 \mathrm{H}, \mathrm{CH}_{3}\right), 1.1-1.5\left(\mathrm{~m}, 2 \mathrm{H}, \mathrm{CH}_{2}\right), 1.6-$ $1.7\left(\mathrm{~m}, 2 \mathrm{H}, \mathrm{N}-\mathrm{CH}_{2}-\mathrm{CH}_{2}\right), 3.1(\mathrm{t}, J=7.81 \mathrm{~Hz}, 2 \mathrm{H}$,
$\left.\mathrm{N}-\mathrm{CH}_{2}-\mathrm{CH}_{2}\right), 3.3\left(\mathrm{t}, J=6.84 \mathrm{~Hz}, 2 \mathrm{H}, \mathrm{S}-\mathrm{CH}_{2}\right), 3.7$ $\left(\mathrm{t}, J=6.84 \mathrm{~Hz}, 2 \mathrm{H}, \mathrm{N}-\mathrm{CH}_{2}\right), 3.8(\mathrm{~m}, 1 \mathrm{H}, \mathrm{NH}), 7.55$ $\left(\mathrm{t}, J=5.86 \mathrm{~Hz}, 1 \mathrm{H}, \mathrm{H}_{\text {arom }}\right), 7.60(\mathrm{t}, J=5.79 \mathrm{~Hz}, 1 \mathrm{H}$, $\left.\mathrm{H}_{\text {arom }}\right), 7.85\left(\mathrm{dd}, J=5.85 \mathrm{~Hz}, J=5.37 \mathrm{~Hz}, 1 \mathrm{H}, \mathrm{H}_{\text {arom }}\right)$, $7.96 \mathrm{ppm}\left(\mathrm{dd}, J=5.86 \mathrm{~Hz}, J=5.37 \mathrm{~Hz}, 1 \mathrm{H}, \mathrm{H}_{\text {arom }}\right)$. ${ }^{13} \mathrm{C}$ NMR $\left(125.66 \mathrm{MHz}, \mathrm{CDCl}_{3}\right): \delta=12.89\left(\mathrm{CH}_{3}\right)$, $19.37\left(\mathrm{CH}_{2}\right), 28.68\left(\mathrm{NH}-\mathrm{CH}_{2}-\mathrm{CH}_{2}\right), 31.83\left(\mathrm{~S}_{-} \mathrm{CH}_{2}\right)$, $48.38\left(\mathrm{NH}-\mathrm{CH}_{2}-\mathrm{CH}_{2}\right), \quad 51.63\left(\mathrm{NH}-\mathrm{CH}_{2}\right), \quad 124.80$, $125.94,126.00,131.51,131.84,132.64\left(\mathrm{CH}_{\text {arom },} \mathrm{C}_{\text {arom }}\right)$, 139.07 (=C-S), 145.32 (=C-Cl), 179.24, $182.21 \mathrm{ppm}$ $(\mathrm{C}=\mathrm{O}) . \mathrm{MS}[+\mathrm{ESI}]: \mathrm{m} / \mathrm{z} 325[\mathrm{M}]^{+}$Anal. Calcd. for $\mathrm{C}_{16} \mathrm{H}_{18} \mathrm{O}_{2} \mathrm{~S}_{1} \mathrm{~N}_{1} \mathrm{Cl}_{1}$ (M, 323.84): C, 59.34; H, 5.60; N, 4.32; S, 9.90. Found: C, 59.40; H, 5.48; N, 4.55, S, 9.78.

$2.5 f \quad 2,3,4,5,6,7,8,9-$ Octahydronaphtho[2,3-e][1,10] dithionine-11,16-dione (10): Compound $\mathbf{1 0}$ was obtained from the reaction of $\mathbf{1}(1 \mathrm{~g}, 4.4 \mathrm{mmol})$ with $9(0.78 \mathrm{~g}, 4.4 \mathrm{mmol})$ according to method 1. Orange solid. M.p.: $170-171^{\circ} \mathrm{C}$. Yield: $0.52 \mathrm{~g}(35 \%) . \mathrm{R}_{f}$ : $0.65\left(\mathrm{CHCl}_{3}\right)$. IR ( $\mathrm{KBr}$ pellet, $\left.\mathrm{cm}^{-1}\right): 3068(\mathrm{Ar}-\mathrm{H})$, 2930, 2897, $2850(\mathrm{C}-\mathrm{H}), 1665(\mathrm{C}=\mathrm{O}), 1594(\mathrm{C}=\mathrm{C})$. ${ }^{1} \mathrm{H}$ NMR $\left(499.74 \mathrm{MHz}, \mathrm{CDCl}_{3}\right): \delta=1.1-1.2(\mathrm{~m}, 8 \mathrm{H}$, $\left.\mathrm{CH}_{2}\right), 1.6\left(\mathrm{~m}, 4 \mathrm{H}, \mathrm{S}-\mathrm{CH}_{2}-\mathrm{CH}_{2}\right), 3.2(\mathrm{t}, J=5.86 \mathrm{~Hz}$, $\left.4 \mathrm{H}, \mathrm{S}-\mathrm{CH}_{2}\right), 7.65(\mathrm{dd}, J=5.37 \mathrm{~Hz}, J=6.84 \mathrm{~Hz}, 2 \mathrm{H}$, $\left.\mathrm{H}_{\text {arom }}\right), 8.05 \mathrm{ppm}(\mathrm{dd}, J=7.32 \mathrm{~Hz}, J=6.84 \mathrm{~Hz}, 2 \mathrm{H}$, $\left.\mathrm{H}_{\text {arom }}\right) .{ }^{13} \mathrm{C} \mathrm{NMR}\left(125.66 \mathrm{MHz}, \mathrm{CDCl}_{3}\right): \delta=21.96$, $24.19\left(\mathrm{CH}_{2}\right), 26.62\left(\mathrm{~S}-\mathrm{CH}_{2}-\mathrm{CH}_{2}\right), 35.41\left(\mathrm{~S}-\mathrm{CH}_{2}\right)$, $126.21,132.09,132.60\left(\mathrm{CH}_{\text {arom, }} \mathrm{C}_{\text {arom }}\right), 149.99$ (=C-S), $177.63 \mathrm{ppm}(\mathrm{C}=\mathrm{O})$. MS [+ESI]: m/z $333[\mathrm{M}]^{+}$. Anal. Calcd. for $\mathrm{C}_{18} \mathrm{H}_{20} \mathrm{O}_{2} \mathrm{~S}_{2}$ (M, 332.48): C, 65.02; H, 6.06; S, 19.28. Found: C, 65.10; H, 6.36; S, 19.13.

$2.5 \mathrm{~g} \quad 7,8,9,10,11,12,13,14,23,24,25,26,27,28,29,30$ Hexadecahydrodinaphtho[2,3-e:2',3'-n] [1,10,13,22] tetrathiacyclotetracosine-5,16,21,32-tetrone (11): Compound $\mathbf{1 1}$ was obtained from the reaction of $\mathbf{1}$ ( $1 \mathrm{~g}, 4.4 \mathrm{mmol})$ with $9(0.78 \mathrm{~g}, 4.4 \mathrm{mmol})$ according to method 1. Red solid. M.p.: $134-135^{\circ} \mathrm{C}$. Yield: $1.4 \mathrm{~g}$ (48\%). $\mathrm{R}_{f}: 0.48\left(\mathrm{CHCl}_{3}\right)$. IR ( $\mathrm{KBr}$ pellet, $\left.\mathrm{cm}^{-1}\right): 3069$ (Ar-H), 2923, $2851(\mathrm{C}-\mathrm{H}), 1654(\mathrm{C}=\mathrm{O}), 1590,1454$ $(\mathrm{C}=\mathrm{C}) .{ }^{1} \mathrm{H}$ NMR $\left(499.74 \mathrm{MHz}, \mathrm{CDCl}_{3}\right): \delta=1.2-1.40$ (m, $\left.16 \mathrm{H}, \mathrm{CH}_{2}\right), 1.4-1.6\left(\mathrm{~m}, 8 \mathrm{H}, \mathrm{S}-\mathrm{CH}_{2}-\mathrm{CH}_{2}\right), 3.2(\mathrm{t}$, $\left.J=7.32 \mathrm{~Hz}, 8 \mathrm{H}, \mathrm{S}-\mathrm{CH}_{2}\right), 7.60(\mathrm{dd}, J=5.85 \mathrm{~Hz}, J=$ $\left.5.37 \mathrm{~Hz}, 4 \mathrm{H}, \mathrm{H}_{\text {arom }}\right), 7.95 \mathrm{ppm}(\mathrm{dd}, J=5.85 \mathrm{~Hz}, J=$ $\left.5.86 \mathrm{~Hz}, 4 \mathrm{H}, \mathrm{H}_{\text {arom }}\right) .{ }^{13} \mathrm{C}$ NMR $\left(125.66 \mathrm{~Hz}, \mathrm{CDCl}_{3}\right)$ : $\delta$ 27.36, $27.82\left(\mathrm{CH}_{2}\right), 29.27\left(\mathrm{~S}^{-} \mathrm{CH}_{2}-\mathrm{CH}_{2}\right), 34.00(\mathrm{~S}-$ $\left.\mathrm{CH}_{2}\right), 125.85,132.05,132.41\left(\mathrm{CH}_{\text {arom }}, \mathrm{C}_{\text {arom }}\right), 147.00$ (=C-S), $177.95 \mathrm{ppm}(\mathrm{C}=\mathrm{O})$. MS [+ESI]: m/z 665 $[\mathrm{M}]^{+}$. Anal. Calcd. for $\mathrm{C}_{36} \mathrm{H}_{40} \mathrm{~S}_{4} \mathrm{O}_{4}(\mathrm{M}, 664.97)$ : $\mathrm{C}$, 65.02; H, 6.06; S, 19.28. Found: C, 65.05; H, 6.10; S, 19.25 . 
2.5h 2-(7-Sulphanyl-4-methyl-coumarinyl)-3-(1-ethoxy)1,4-naphthoquinone (13): Compound 13 was synthesized from the reaction of $\mathbf{1}(0.5 \mathrm{~g}, 2.2 \mathrm{mmol})$ with $\mathbf{1 2}$ $(0.42 \mathrm{~g}, 2.2 \mathrm{mmol})$ according to method 1 . Red crystal. M.p.: $194-195^{\circ} \mathrm{C}$. Yield: $0.35 \mathrm{~g}(40 \%) . \mathrm{R}_{f}$ : 0.65 $\left(\mathrm{CH}_{2} \mathrm{Cl}_{2}\right)$. IR ( $\mathrm{KBr}$ pellet, $\left.\mathrm{cm}^{-1}\right): 3071(\mathrm{Ar}-\mathrm{H}), 2918$, $2849(\mathrm{C}-\mathrm{H}), 1720,1667(\mathrm{C}=\mathrm{O}), 1600,1551(\mathrm{C}=\mathrm{C}) .{ }^{1} \mathrm{H}$ NMR $\left(499.74 \mathrm{MHz}, \mathrm{CDCl}_{3}\right): \delta=1.2(\mathrm{t}, J=6.83 \mathrm{~Hz}$, $\left.3 \mathrm{H}, \mathrm{O}-\mathrm{CH}_{2}-\mathrm{CH}_{3}\right), 2.3\left(\mathrm{~s}, 3 \mathrm{H}, \mathrm{CH}_{3}\right), 4.5$ (q, $2 \mathrm{H}, \mathrm{O}-\mathrm{CH}_{2}-$ $\left.\mathrm{CH}_{3}\right), 6.1(\mathrm{~s}, 1 \mathrm{H}, \mathrm{CH}), 7.1\left(\mathrm{t}, J=5.60 \mathrm{~Hz}, 1 \mathrm{H}, \mathrm{H}_{\text {arom }}\right)$, $7.2\left(\mathrm{t}, J=6.84 \mathrm{~Hz}, 2 \mathrm{H}, \mathrm{H}_{\text {arom }}\right), 7.4(\mathrm{dd}, J=7.84 \mathrm{~Hz}$, $\left.J=7.32 \mathrm{~Hz}, 1 \mathrm{H}, \mathrm{H}_{\text {arom }}\right), 7.65(\mathrm{dd}, J=6.34 \mathrm{~Hz}$, $\left.J=5.83 \mathrm{~Hz}, 2 \mathrm{H}, \mathrm{H}_{\text {arom }}\right), 8.00(\mathrm{dd}, J=7.32 \mathrm{~Hz}, J=$ $\left.6.84 \mathrm{~Hz}, 1 \mathrm{H}, \mathrm{H}_{\text {arom }}\right) .{ }^{13} \mathrm{C}$ NMR $\left(125.66 \mathrm{MHz}, \mathrm{CDCl}_{3}\right)$ : $\delta=14.81\left(\mathrm{O}-\mathrm{CH}_{2}-\mathrm{CH}_{3}\right), 17.54\left(\mathrm{CH}_{3}\right), 69.82\left(\mathrm{O}-\mathrm{CH}_{2}\right)$, 117.31, 123.69, $123.80125 .79,125.98,126.52,130.37$, $131.03,132.78,133.30\left(\mathrm{CH}_{\text {arom }}, \mathrm{C}_{\text {arom }}\right), 113.57(\mathrm{CH})$, $115.79\left(=\mathrm{C}-\mathrm{CH}_{3}\right), 139.21(=\mathrm{C}-\mathrm{S}), 150.93\left(\mathrm{~S}-\mathrm{C}_{\text {arom }}\right)$, 152.59 (=C-O), $159.79(\mathrm{C}=\mathrm{O}), 178.62,180.18 \mathrm{ppm}$ $(\mathrm{C}=\mathrm{O}) . \mathrm{MS}[+\mathrm{ESI}]: \mathrm{m} / \mathrm{z} 393[\mathrm{M}]^{+}, 365[\mathrm{M}-28]^{+}$. Anal. Calcd. for $\mathrm{C}_{22} \mathrm{H}_{16} \mathrm{O}_{5} \mathrm{~S}_{1}$ (M, 392.43): C, 67.33; H, 4.11; S, 8.17. Found: C, 67.41; H, 4.08; S, 8.25.

2.5i 2,3-Bis(7-sulphanyl-4-methyl-coumarinyl)-1,4 -naphthoquinone (14): Compound 14 was synthesized from the reaction of $\mathbf{1}(0.5 \mathrm{~g}, 2.2 \mathrm{mmol})$ with $12(0.42 \mathrm{~g}, 2.2 \mathrm{mmol})$ according to method 1. Dark brown solid. M.p.: $270-271^{\circ} \mathrm{C}$. Yield: $0.6 \mathrm{~g}$ (51\%). $\mathrm{R}_{f}: 0.45\left(\mathrm{CH}_{2} \mathrm{Cl}_{2}\right)$. IR ( $\mathrm{KBr}$ pellet, $\left.\mathrm{cm}^{-1}\right): 3080$ (Ar-H), 2972, 2950 (C-H), 1733, 1660 (C=O), 1601, $1546(\mathrm{C}=\mathrm{C}) .{ }^{1} \mathrm{H}$ NMR $\left(499.74 \mathrm{MHz}, \mathrm{CDCl}_{3}\right): \delta=$ $2.3\left(\mathrm{~s}, 6 \mathrm{H}, \mathrm{CH}_{3}\right), 6.2(\mathrm{~s}, 2 \mathrm{H}, \mathrm{CH}), 7.2(\mathrm{dd}, J=$ $\left.7.81 \mathrm{~Hz}, J=8.3 \mathrm{~Hz}, 2 \mathrm{H}, \mathrm{H}_{\text {arom }}\right), 7.4(\mathrm{~d}, J=8.3 \mathrm{~Hz}$, $\left.4 \mathrm{H}, \mathrm{H}_{\text {arom }}\right), 7.7(\mathrm{dd}, J=5.86 \mathrm{~Hz}, J=5.85 \mathrm{~Hz}, 2 \mathrm{H}$, $\left.\mathrm{H}_{\text {arom }}\right) 7.95 \mathrm{ppm}(\mathrm{dd}, J=5.85 \mathrm{~Hz}, J=5.37 \mathrm{~Hz}$, $\left.2 \mathrm{H}, \mathrm{H}_{\text {arom }}\right) \cdot{ }^{13} \mathrm{C}$ NMR $\left(125.66 \mathrm{MHz}, \mathrm{CDCl}_{3}\right): \delta=$ $17.57\left(\mathrm{CH}_{3}\right), 114.32(\mathrm{CH}), 117.27\left(=\mathrm{C}-\mathrm{CH}_{3}\right), 118.36$, 124.20, 124.88, 126.58, 131.45, 133.37, 137.22, 147.38 $\left(\mathrm{CH}_{\text {arom }}, \mathrm{C}_{\text {arom }}\right), 150.74$ (=C-S $), 152.59(\mathrm{~S}-\mathrm{C}=), 159.00$ $(\mathrm{C}=\mathrm{O}), \quad 177.13 \mathrm{ppm} \quad(\mathrm{C}=\mathrm{O}) . \quad \mathrm{MS}[-\mathrm{ESI}]: \mathrm{m} / \mathrm{z} 538$ $[\mathrm{M}]^{+}$. Anal. Calcd. for $\mathrm{C}_{30} \mathrm{H}_{18} \mathrm{O}_{6} \mathrm{~S}_{2}(\mathrm{M}, 538.601)$ : C, 66.90; H, 3.36; S, 11.90. Found: C, 66.71; H, 3.18; S, 11.85 .

2.5j 2,3,6-Tris(11-sulphanyl-1-undecanol)-5-ethoxy-1, 4-benzoquinone (16): Compound $\mathbf{1 6}$ was synthesized from the reaction of $\mathbf{1 5}(0.6 \mathrm{~g}, 2.4 \mathrm{mmol})$ with $2(1.96 \mathrm{~g}, 9.5 \mathrm{mmol})$ according to method 1 . Yellowbrown solid. M.p.: $60-61{ }^{\circ} \mathrm{C}$. Yield: $0.5 \mathrm{~g}(27 \%) . \mathrm{R}_{f}$ : 0.65 [EtAc/ $\mathrm{CH}_{2} \mathrm{Cl}_{2}$ (2:1)]. IR ( $\mathrm{KBr}$ pellet, $\mathrm{cm}^{-1}$ ): 3311 $(\mathrm{OH}), 2917,2849(\mathrm{C}-\mathrm{H}), 1659(\mathrm{C}=\mathrm{O}), 1567(\mathrm{C}=\mathrm{C}) .{ }^{1} \mathrm{H}$ NMR $\left(499.74 \mathrm{MHz}, \mathrm{CDCl}_{3}\right): \delta=1.1(\mathrm{t}, J=7.32 \mathrm{~Hz}$, $\left.3 \mathrm{H}, \mathrm{CH}_{3}\right), 1.2-1.3\left(\mathrm{~m}, 42 \mathrm{H}, \mathrm{CH}_{2}\right), 1.4-1.5(\mathrm{~m}, 6 \mathrm{H}$, $\left.\mathrm{S}-\mathrm{CH}_{2}-\mathrm{CH}_{2}\right), 1.7(\mathrm{~s}, 3 \mathrm{H}, \mathrm{OH}), 3.0(\mathrm{t}, J=7.32 \mathrm{~Hz}, 6 \mathrm{H}$, $\left.\mathrm{S}_{-} \mathrm{CH}_{2}\right), 3.6\left(\mathrm{t}, J=6.83 \mathrm{~Hz}, 6 \mathrm{H}, \mathrm{HO}-\mathrm{CH}_{2}\right), 4.2 \mathrm{ppm}$ (q, $\left.2 \mathrm{H}, \mathrm{O}-\mathrm{CH}_{2}-\mathrm{CH}_{3}\right) .{ }^{13} \mathrm{C} \mathrm{NMR}\left(125.66 \mathrm{MHz}, \mathrm{CDCl}_{3}\right.$ ): $\delta=14.77\left(\mathrm{CH}_{3}\right), 24.74,24.76,24.77,27.66,27.68$, $27.71,28.14,28.39,28.15,28.42,28.43,28.46,28.48$, 28.51, 28.54, 28.56, 28.58, 29.21, 29.44, $29.49\left(\mathrm{CH}_{2}\right)$, $31.79\left(\mathrm{~S}-\mathrm{CH}_{2}-\mathrm{CH}_{2}\right), \quad 31.93\left(\mathrm{HO}-\mathrm{CH}_{2}-\mathrm{CH}_{2}\right), 32.01$, 33.55, $33.88\left(\mathrm{~S}^{-} \mathrm{CH}_{2}\right), 61.96\left(\mathrm{HO}-\mathrm{CH}_{2}\right), 68.76(\mathrm{O}-$ $\mathrm{CH}_{2}$ ), 130.67, 141.37, 146.18 (=C-S), 155.68 (=C-O), 173.99, $177.72 \mathrm{ppm}(\mathrm{C}=\mathrm{O})$. MS [-ESI]: $\mathrm{m} / \mathrm{z} 758$ $[\mathrm{M}]^{+}, 712[\mathrm{M}-45]^{+}$. Anal. Calcd. for $\mathrm{C}_{41} \mathrm{H}_{74} \mathrm{O}_{6} \mathrm{~S}_{3}(\mathrm{M}$, 759.23): C, 64.86; H, 9.82; S, 12.66. Found: C, 64.90; H, 9.76; S, 12.43 .

2.5k 2,3,5,6-Tetrakis(11-sulphanyl-1-undecanol)-1,4benzoquinone (17): Compound 17 was synthesized from the reaction of $\mathbf{1 5}(0.6 \mathrm{~g}, 2.4 \mathrm{mmol})$ with $\mathbf{2}$ $(1.96 \mathrm{~g}, 9.5 \mathrm{mmol})$ according to method 1 . Yellowgreen solid. M.p.: $85-86^{\circ} \mathrm{C}$. Yield: $1.4 \mathrm{~g}(63 \%)$. $\mathrm{R}_{f}$ : 0.45 [EtAc/ $\mathrm{CH}_{2} \mathrm{Cl}_{2}(2: 1)$ ]. IR ( $\mathrm{KBr}$ pellet, $\left.\mathrm{cm}^{-1}\right): 3279$ $(\mathrm{OH}), 2917,2848(\mathrm{C}-\mathrm{H}), 1656(\mathrm{C}=\mathrm{O}), 1484(\mathrm{C}=\mathrm{C})$. ${ }^{1} \mathrm{H}$ NMR (499.74 MHz, $\left.\mathrm{CDCl}_{3}\right): \delta=1.1-1.3(\mathrm{~m}, 56 \mathrm{H}$, $\left.\mathrm{CH}_{2}\right), 1.3-1.4\left(\mathrm{~m}, 8 \mathrm{H}, \mathrm{S}-\mathrm{CH}_{2}-\mathrm{CH}_{2}\right), 1.52(\mathrm{~s}, 4 \mathrm{H}, \mathrm{OH})$, $3.0\left(\mathrm{t}, J=7.32 \mathrm{~Hz}, 8 \mathrm{H}, \mathrm{S}-\mathrm{CH}_{2}\right), 3.6(\mathrm{t}, J=6.34 \mathrm{~Hz}$, $\left.8 \mathrm{H}, \mathrm{HO}-\mathrm{CH}_{2}\right) \cdot{ }^{13} \mathrm{C}$ NMR $\left(125.66 \mathrm{MHz}, \mathrm{CDCl}_{3}\right): \delta=$ 24.76, 27.74, 28.18, 28.43, 28.51, 28.52, $28.59\left(\mathrm{CH}_{2}\right)$, $29.54\left(\mathrm{~S}-\mathrm{CH}_{2}-\mathrm{CH}_{2}\right), 31.80\left(\mathrm{HO}-\mathrm{CH}_{2}-\mathrm{CH}_{2}\right), 33.38(\mathrm{~S}-$ $\left.\mathrm{CH}_{2}\right), 62.02\left(\mathrm{HO}-\mathrm{CH}_{2}\right), 145.07$ (=C-S), $173.35 \mathrm{ppm}$ $(\mathrm{C}=\mathrm{O})$. MS [+ESI]: m/z $918[\mathrm{M}]^{+}$. Anal. Calcd. for $\mathrm{C}_{50} \mathrm{H}_{92} \mathrm{O}_{6} \mathrm{~S}_{4}$ (M, 917.54): C, 65.45; H, 10.10; S, 13.97 . Found: C, 65.50; H, 10.26; S, 13.23.

\section{Results and discussion}

The reaction of 2,3-dichloro-1,4-naphthoquinone $\mathbf{1}$ with 11-mercapto-1-undecanol 2 in ethanol in the presence of $\mathrm{Na}_{2} \mathrm{CO}_{3}$ gave $\mathrm{S}$, O-substituted-1,4-naphthoquinone 3 and $\mathrm{S}, \mathrm{S}$-substituted-1,4-naphthoquinone $\mathbf{4}$. Ethoxy substituted mono(thio)-1,4-naphthoquinone $\mathbf{1 3}$ and bis(thio)substituted-1,4-naphthoquinone $\mathbf{1 4}$ were obtained from the reaction of $\mathbf{1}$ with $\mathbf{1 2}$ in EtOH/ $\mathrm{Na}_{2} \mathrm{CO}_{3}$. In these reactions, mono(thio)-substituted compounds containing chlorine atom derivatives were not observed potentially due to the decreased thiol amount in the medium of the reaction, while the ethoxy derivatives of mono(thio)-substituted compounds were obtained successfully. While compounds $\mathbf{3}$ and $\mathbf{1 3}$ were formed, one chloro atom was replaced with ethoxy groups, which acted as a nucleophilic compound. 
Compounds 6, 7 and 8 were obtained from the reaction of 1 with 2-(butylamino)ethanethiol 5. For compounds $\mathbf{6}$ and 7, no bands were observed in the region $3200-3450 \mathrm{~cm}^{-1}$ attributable to the streching vibration of the bonded $\mathrm{NH}$ group, indicating that the formation of cyclization reaction had taken place yielding the compounds $\mathbf{6}$. It was shown that interesting heterocylic compounds $\mathbf{1 0}$ and $\mathbf{1 1}$ could be obtained from the reaction of 2,3-dichloro-1,4-naphthoquinone 1 with long alkyl chain dithiol 9. Isolation and identification proved that a cyclization reaction had taken place, yielding the compound $\mathbf{1 0}$ and intramolecular cyclization to yield heterocyclic diquinone $\mathbf{1 1}$ (scheme 1). The ethoxy substituted-tris(thio)-1,4-benzoquinone $\mathbf{1 6}$ and tetrakis(thio)-substituted-1,4-benzoquinone $\mathbf{1 7}$ compounds were obtained from the reaction of p-chloranil 15 with 11-mercapto-1-undecanol 2 via vinilic substitution (scheme 2).

FT-IR spectrum in $\mathrm{KBr}$ showed the following important absorption bands. In the IR spectra of synthesized compounds two typical strong quinonic carbonyl absorptions were observed between at 1654 and $1667 \mathrm{~cm}^{-1}$. Compounds $\mathbf{1 3}$ and $\mathbf{1 4}$ gave strong and sharp carbonyl bands at $1667,1660 \mathrm{~cm}^{-1}$ and at 1720 , $1733 \mathrm{~cm}^{-1}$ which were due to coumarine ring. The NH absorption appeared at $3344 \mathrm{~cm}^{-1}$ for compound $\mathbf{8}$. The IR spectra of compounds $3,4,16$ and 17 showed broad bands at $3410,3314,3312$ and $3279 \mathrm{~cm}^{-1}$ for the $-\mathrm{OH}$ streching, respectively.

The ${ }^{1} \mathrm{H}$ spectrum of the products in $\mathrm{CDCl}_{3}$ displayed distinct signals with appropriate multiplets. ${ }^{1} \mathrm{H}$ NMR signal of the hydrogen atoms of the methylene group (S$\mathrm{CH}_{2}$ ) adjacent to the sulphur atom in compound $\mathbf{1 1}$ was shifted to a higher field and displayed triplet at $3.2 \mathrm{ppm}$ $(J=7.32 \mathrm{~Hz})$. The ${ }^{13} \mathrm{C}$ NMR spectra of compound 13 gave two carbonyl signals at 178.62 and $180.18 \mathrm{ppm}$ $(\mathrm{C}=\mathrm{O})$ while compound $\mathbf{1 4}$ showed one carbonyl signal at $177.3 \mathrm{ppm}(\mathrm{C}=\mathrm{O})$ in naphthoquinone unit.

The positive ion mode of ESI mass spectrum of the compound $\mathbf{3}$ and the respective molecular ion peak was observed at $\mathrm{m} / z(\%) 405(100)[\mathrm{M}]^{+}$. The cleavage of ethoxy group from compound $\mathbf{3}$ of the molecular ion gave to rise fragment $F_{1}$ at $m / z(\%) 359$ (100) which was the base peak. The respective molecular ion peak was observed at m/z (\%) 918 (100) for compound 17 in the mode of ESI.

\subsection{Absorption and fluorescence spectroscopy}

The absorption parameters of compounds $\mathbf{3}, \mathbf{4}, \mathbf{6}, \mathbf{7}, \mathbf{8}$, $10,11,13,14,16$ and 17 in different solutions were reported in table 4 . The electronic absorption spectra of $6,7,8$ showed the expected naphthoquinone bands in the UV region around $240-248 \mathrm{~nm}$ and $300-347 \mathrm{~nm}$ $\left(\pi-\pi^{*}\right.$ electronic transitions) in chloroform. In addition, a third energy transition appeared as a broad band in the visible region between 451 and $554 \mathrm{~nm}$ (see table 4). This absorption was typical of aminosubstituted benzoquinones, naphthoquinones and anthraquinones and is assigned to charge transfer (CT) transitions and weak $n-\pi *$ transitions of the carbonyl group in the quinone. ${ }^{23} \mathrm{~A}$ broad band in the visible region at $535 \mathrm{~nm}$ in tetrahydrofurane, $554 \mathrm{~nm}$ in chloroform and $549 \mathrm{~nm}$ in methanol for compound 6 show strong bathochromic shift relative to compounds $\mathbf{7}$ and 8. This bathochromic shift was due to $\mathrm{N}, \mathrm{S}$-substituted cyclo group in quinone unit of compound $\mathbf{6}$. The absorption spectra of $\mathbf{1 3}$ and $\mathbf{1 4}$ display the intense bands having maxima between 278 and $331 \mathrm{~nm}$ and a shoulder of lower intensity between 451 and $463 \mathrm{~nm}$. Ethoxy substituted naphthoquinone compound $\mathbf{1 3}$ was considerably red-shifted at 243 and $329 \mathrm{~nm}$ in the UV region relative to compound $\mathbf{1 4}$ which absorbs around at 237 and $326 \mathrm{~nm}$, respectively in THF.

The fluorescence excitation and emission maxima of compounds $3,4,6,7,8,10,11,13,14,16$ and 17 in $\mathrm{CHCl}_{3} / \mathrm{MetOH}(1: 1)$ solution were summarized in table 5. Fluorescence is an important property of quinone compounds for the use of organic materials. ${ }^{24,25}$ The spectrum was composed of two broad bands and comparable to those of the similar compounds. ${ }^{26,27}$

Figure 2 shows the excitation and the emission of $\mathbf{1 3}$ in $\mathrm{CHCl}_{3} / \mathrm{MetOH}(1: 1)$. The first band at $327 \mathrm{~nm}$ was the fluorescence characteristic of the coumarin ring substituted naphthoquinone assigned to the excited band and the second band at $398 \mathrm{~nm}$ was emission band at room temperature.

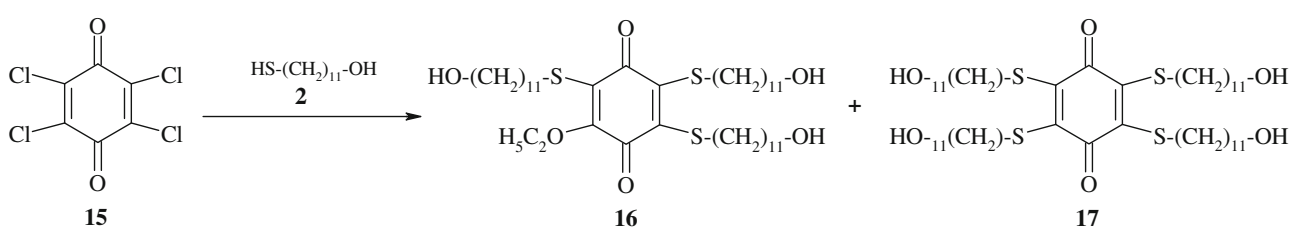

Scheme 2. Synthesis of compounds $\mathbf{1 6}$ and $\mathbf{1 7}$. 
Table 4. UV-Vis data of compounds $3,4,6,7,8,10,11,13,14,16$ and 17 in different solvents.

\begin{tabular}{lccc}
\hline Compound & $\lambda^{\mathrm{a}}(\log \varepsilon)$ & $\lambda^{\mathrm{b}}(\log \varepsilon)$ & $\lambda^{\mathrm{c}}(\log \varepsilon)$ \\
\hline $\mathbf{3}$ & $241(4.2), 266(4.2) 335(3.5)$, & $241(4.2), 273(4.2) 338(3.5)$, & $238(3.7), 264(3.8) 333(3.1)$, \\
& $443(3.5)$ & $457(3.4)$ & $444(2.9)$ \\
$\mathbf{4}$ & $241(4.5), 281(4.5) 335(4.0)$, & $242(4.2), 281(4.2) 344(3.6)$, & $241(3.9), 276(3.9) 343(3.3)$, \\
& $467(3.9)$ & $471(3.6)$ & $460(3.3)$ \\
$\mathbf{6}$ & $239(4.2), 298(4.3) 535(3.4)$ & $240(3.5), 300(3.7) 554(2.9)$ & $236(3.6), 298(3.8) 549(2.9)$ \\
$\mathbf{7}$ & $236(3.9), 339(3.3) 471(2.9)$ & $241(4.2), 345(3.6) 483(3.2)$ & $223(3.8), 267(3.6) 341(3.1)$, \\
$\mathbf{8}$ & $246(3.8), 342(2.9) 451(2.8)$ & $248(3.4), 347(3.3) 451(2.9)$ & $460(2.7)$ \\
$\mathbf{1 0}$ & $245(3.0), 266(2.9) 312(2.5)$, & $248(3.7), 269(3.7) 315(3.2)$, & - \\
$\mathbf{1 1}$ & $449(2.3)$ & $453(3.1)$ & $247(3.8), 266(3.7) 313(3.2)$, \\
$\mathbf{1 3}$ & $241(3.6), 270(2.7) 343(3.0)$, & $257(3.8), 279(4.0) 344(3.4)$, & $445(3.1)$ \\
$\mathbf{1 4}$ & $462(3.0)$ & $467(3.4)$ & - \\
$\mathbf{1 6}$ & $243(3.6), 281(3.5) 329(3.5)$, & $244(4.5), 282(4.5) 331(4.5)$, & $241(3.7), 278(3.7) 330(3.7)$, \\
$\mathbf{1 7}$ & $451(2.6)$ & $463(3.6)$ & $450(2.7)$ \\
& $237(4.0), 326(4.0) 451(3.1)$ & $240(3.5), 267(3.4) 326(3.5)$, & $22(4.3), 279(3.6) 326(3.7)$ \\
& $225(3.7), 245(3.9) 396(3.5)$ & $229(4.4), 244(4.4) 401(3.9)$ & $210(4.0), 245(4.0) 396(3.7)$ \\
& $223(3.2), 241(3.1) 401(2.8)$ & $225(3.5), 240(3.7) 405(3.5)$ & $210(3.6), 240(3.7) 401(3.5)$ \\
\hline
\end{tabular}

${ }^{\mathrm{a}} \mathrm{THF} ;{ }^{\mathrm{b}} \mathrm{CHCl}_{3} ;{ }^{\mathrm{c}} \mathrm{MetOH}$.

$(-) ; \mathbf{8}$ and 11 were dissolved in $\mathrm{MetOH}$

\section{$3.2 X$-ray study}

The compound $\mathbf{1 3}$ was crystallized in the triclinic crystal system (space group P-1) with the unit cell parameters $\mathrm{a}=8.4474(2) \AA, \mathrm{b}=$ 9.1257(1) $\AA, \mathrm{c}=$ 11.9197(2) $\AA, \alpha=84.474(4)^{\circ}, \beta=84.506(4)^{\circ}, \gamma=$ $80.473(4)^{\circ}, V=899.00(3) \AA^{3}, Z=2$. The structure was solved by direct methods (SIR92) and refined to the residual index $\mathrm{R}_{1}=0.056$. Drawings were prepared with the program ORTEP-III ${ }^{21}$ with $50 \%$ probability displacement elipsoide for compound $\mathbf{1 3}$ in figure 1 .

Table 5. Fluorescence data of the compounds $3,4,6,7,8$, $10,11,13,14,16$ and 17.

\begin{tabular}{lccc}
\hline Compound & Solvent $(1: 1)$ & $\begin{array}{c}\lambda_{\max }(\mathrm{ex} .) \\
(\mathrm{nm})\end{array}$ & $\begin{array}{c}\lambda_{\max }(\mathrm{em} .) \\
(\mathrm{nm})\end{array}$ \\
\hline $\mathbf{3}$ & $\mathrm{CHCl}_{3} / \mathrm{MetOH}$ & 221 & 455 \\
$\mathbf{4}$ & $\mathrm{CHCl}_{3} / \mathrm{MetOH}$ & 220 & 456 \\
$\mathbf{6}$ & $\mathrm{CHCl}_{3} / \mathrm{MetOH}$ & 226,268 & 453,535 \\
$\mathbf{7}$ & $\mathrm{CHCl}_{3} / \mathrm{MetOH}$ & 246 & 494 \\
$\mathbf{8}$ & $\mathrm{CHCl}_{3} / \mathrm{MetOH}$ & 249 & 497 \\
$\mathbf{1 0}$ & $\mathrm{CHCl}_{3} / \mathrm{MetOH}$ & 261 & 417 \\
$\mathbf{1 1}$ & $\mathrm{CHCl}_{3} / \mathrm{MetOH}$ & 245 & 494 \\
$\mathbf{1 3}$ & $\mathrm{CHCl}_{3} / \mathrm{MetOH}$ & 327 & 398 \\
$\mathbf{1 4}$ & $\mathrm{CHCl}_{3} / \mathrm{MetOH}$ & 327 & 390 \\
$\mathbf{1 6}$ & $\mathrm{CHCl}_{3} / \mathrm{MetOH}$ & 221 & 457 \\
$\mathbf{1 7}$ & $\mathrm{CHCl}_{3} / \mathrm{MetOH}$ & 222 & 458 \\
\hline
\end{tabular}

The standard average $\mathrm{C}-\mathrm{C}$ bond distance in a flat six carbon atom containing aromatic ring is $1.395(1)$ $\AA$. The double bond distance of C1-C2 was 1.354(2) $\AA$ in 13, which was smaller than expected due to substituents such as $=\mathrm{O}$. The double bond length of the quinone moiety agreed well with corresponding distance in a similar compound. ${ }^{28}$ Crystal data and refinement parameters for compound $\mathbf{1 3}$ were summarized in table 1 . The selected bond distances, bond and torsion angles for compound $\mathbf{1 3}$ are listed in tables 2 and 3, respectively. The bond lengths of $\mathrm{C} 3-\mathrm{O} 2, \mathrm{C} 10-\mathrm{O} 1$ and C18-O5 were 1.212(2) $\AA, 1.220(2) \AA$, and 1.209(1) $\AA$, respectively, typical of $\mathrm{C}=\mathrm{O}$ bonds. In the compound $13, \mathrm{C}-\mathrm{C}-\mathrm{C}$ and $\mathrm{C}-\mathrm{C}-\mathrm{O}$ angles were very close to $120^{\circ}$, as expected for $\mathrm{sp}^{2}$ hybridized atoms. In the structure of the compound, the $U_{\text {eq }}$ values of the C atoms of the ethoxy chain generally increase on going

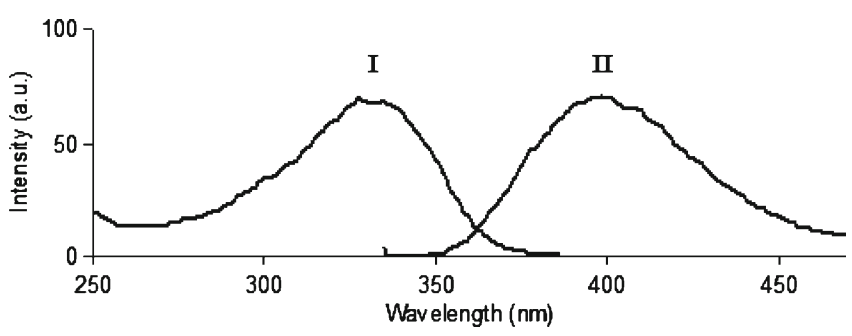

Figure 2. The excitation (I) and emission (II) spectra of $\mathbf{1 3}$ $\left(2 \times 10^{-4} \mathrm{M}\right)$ in $\mathrm{CHCl}_{3} / \mathrm{MetOH}(1: 1)$ at room temperature. 
from $\mathrm{C} 21$ to $\mathrm{C} 22$, reflecting libration of the chain. The both rings of naphthoquinone unit were planar with a maximum deviations of $0.0157(1) \AA$ (plane $1=\mathrm{C} 1$ C2-C3-C4-C9-C10) and 0.0045(1) $\AA$ (plane 2 = C4C5-C6-C7-C8-C9). The substituted coumarine ring was planar with a maximum deviation of 0.0024(1) $\AA$ (plane $3=\mathrm{C} 11-\mathrm{C} 12-\mathrm{C} 13-\mathrm{C} 14-\mathrm{C} 19-\mathrm{C} 20)$ and $0.0139(1) \AA$ (plane $4=\mathrm{C} 14-\mathrm{C} 15-\mathrm{C} 17-\mathrm{C} 18-\mathrm{O} 4-\mathrm{C} 19)$. Dihedral angles were $64.54(1)^{\circ}$ between planes 1 and 3 , 63.61 $(1)^{\circ}$ between planes 2 and 4 .

\subsection{Electrochemical study}

Cyclic voltammetry measurements of $\mathbf{1}, \mathbf{3}, \mathbf{4}, \mathbf{6}, \mathbf{7}$, $8,10,11,13,14,15,16$ and 17 were performed in
DMF to explore the substituent effects on their redox potentials. The voltammetric data of these compounds; cathodic peak potentials $\left(E_{\mathrm{pc}}\right)$, anodic peak potentials $\left(E_{\mathrm{pa}}\right)$ versus glassy carbon electrode (GCE), half-wave peak potentials $\left(E_{1 / 2}\right)$, the difference between the first oxidation and reduction processes $\left(\Delta E_{\mathrm{p}}\right)$ and cathodic $v s$. anodic peak current ratio $\left(i_{\mathrm{pc}} / i_{\mathrm{pa}}\right)$ were shown in table 6. Experiments using a glassy carbon electrode were performed in order to investigate the electrooxidizable groups and to complete the information in the presence of proton sources. Additional oxidation waves were discernible.

Electrochemical study, cyclic voltammetry was performed in aprotic medium and the unsubstituted quinones 2,3-dichloro-1,4-naphthoquinone 1 and $p$ chloranil 15 were used as standarts. Compounds 1 and

Table 6. Voltammetric parameters in DMF/TBAP $0.1 \mathrm{M}, \mathrm{v}=0.1 \mathrm{~V} \mathrm{~s}^{-1}$.

\begin{tabular}{|c|c|c|c|c|c|}
\hline Compound & $-\left(E_{\mathrm{pc}}\right)^{\mathrm{a}}$ & $-\left(E_{\mathrm{pa}}\right)^{\mathrm{a}}$ & $-\left(E_{1 / 2}\right)^{\mathrm{a}}$ & $\left(\Delta E_{\mathrm{p}}\right)^{\mathrm{b}}$ & $\left(i_{\mathrm{pc}} / i_{\mathrm{pa}}\right)^{\mathrm{c}}$ \\
\hline \multirow[t]{2}{*}{ 2,3-Dichloro-1,4-naphthoquinone $\mathbf{1}$} & $0.287^{\mathrm{d}}$ & $0.189^{\mathrm{d}}$ & 0.238 & 0.097 & 0.992 \\
\hline & $1.074^{\mathrm{d}}$ & $0.973^{\mathrm{d}}$ & 1.023 & 0.099 & 2.034 \\
\hline p-chloranil 15 & $0.730^{\mathrm{d}}$ & $0.644^{\mathrm{d}}$ & 0.687 & 0.085 & 1.659 \\
\hline \multirow[t]{3}{*}{3} & $0.408^{\mathrm{d}}$ & $0.353^{\mathrm{d}}$ & 0.381 & 0.055 & 1.141 \\
\hline & $0.592^{\mathrm{d}}$ & $0.536^{\mathrm{d}}$ & 0.564 & 0.055 & 1.624 \\
\hline & 1.349 & - & - & - & - \\
\hline \multirow[t]{2}{*}{4} & $0.540^{\mathrm{d}}$ & $0.465^{\mathrm{d}}$ & 0.498 & 0.075 & 1.254 \\
\hline & 1.187 & - & - & - & - \\
\hline \multirow[t]{2}{*}{6} & $0.804^{\mathrm{d}}$ & $0.726^{\mathrm{d}}$ & 0.765 & 0.077 & 1.028 \\
\hline & 1.367 & - & - & - & - \\
\hline \multirow[t]{4}{*}{7} & $0.815^{\mathrm{d}}$ & $0.502^{\mathrm{d}}$ & 0.658 & 0.313 & 1.058 \\
\hline & 1.277 & 1.796 & - & - & - \\
\hline & 1.916 & - & - & - & - \\
\hline & 2.258 & - & - & - & - \\
\hline \multirow[t]{2}{*}{8} & $0.550^{\mathrm{d}}$ & $0.255^{\mathrm{d}}$ & 0.403 & 0.295 & 1.055 \\
\hline & 0.872 & 0.594 & - & - & - \\
\hline \multirow[t]{2}{*}{10} & $0.506^{\mathrm{d}}$ & $0.433^{\mathrm{d}}$ & 0.470 & 0.073 & 1.238 \\
\hline & 1.213 & - & - & - & - \\
\hline \multirow[t]{2}{*}{11} & $0.564^{\mathrm{d}}$ & $0.463^{\mathrm{d}}$ & 0.513 & 0.102 & 1.109 \\
\hline & 0.848 & - & - & - & - \\
\hline \multirow[t]{4}{*}{13} & $0.473^{\mathrm{d}}$ & $0.403^{\mathrm{d}}$ & 0.438 & 0.069 & 1.057 \\
\hline & 1.088 & - & - & - & - \\
\hline & 1.898 & - & - & - & - \\
\hline & 2.185 & - & - & - & - \\
\hline \multirow[t]{3}{*}{14} & $0.283^{\mathrm{d}}$ & $0.209^{\mathrm{d}}$ & 0.246 & 0.073 & 0.946 \\
\hline & 0.909 & - & - & - & - \\
\hline & 1.271 & - & - & - & - \\
\hline \multirow[t]{2}{*}{16} & $0.403^{\mathrm{d}}$ & $0.325^{\mathrm{d}}$ & 0.364 & 0.077 & 1.004 \\
\hline & 1.129 & - & - & - & - \\
\hline \multirow[t]{2}{*}{17} & $0.374^{\mathrm{d}}$ & $0.301^{\mathrm{d}}$ & 0.337 & 0.073 & 1.085 \\
\hline & 1.039 & - & - & - & - \\
\hline
\end{tabular}

${ }^{a}$ Peak potential $(\mathrm{V} v s . \mathrm{Ag} / \mathrm{AgCl})$ at room temperature as determined by cyclic voltammetry at a GC electrode and given without $i \mathrm{R}$ drop correction, $E_{1 / 2}$ (approximated by $\left(E_{\mathrm{pa}}+E_{\mathrm{pc}}\right) / 2$ ) in $\mathrm{V} v s$. $\mathrm{Ag} / \mathrm{AgCl}$; supporting electrolyte tetrabutyl ammonium perchlorate $(0.1 \mathrm{M})$ in DMF, scan rate $0.1 \mathrm{~V} \mathrm{~s}^{-1}$ concentration of compounds $10^{-4} \mathrm{M} .{ }^{\mathrm{b}}\left(E_{\mathrm{pa}}-E_{\mathrm{pc}}\right)$ in $\mathrm{V}$. ${ }^{\mathrm{c}}$ Cathodic $v s$. anodic peak current ratio. ${ }^{\mathrm{d}}$ Reversible wave 


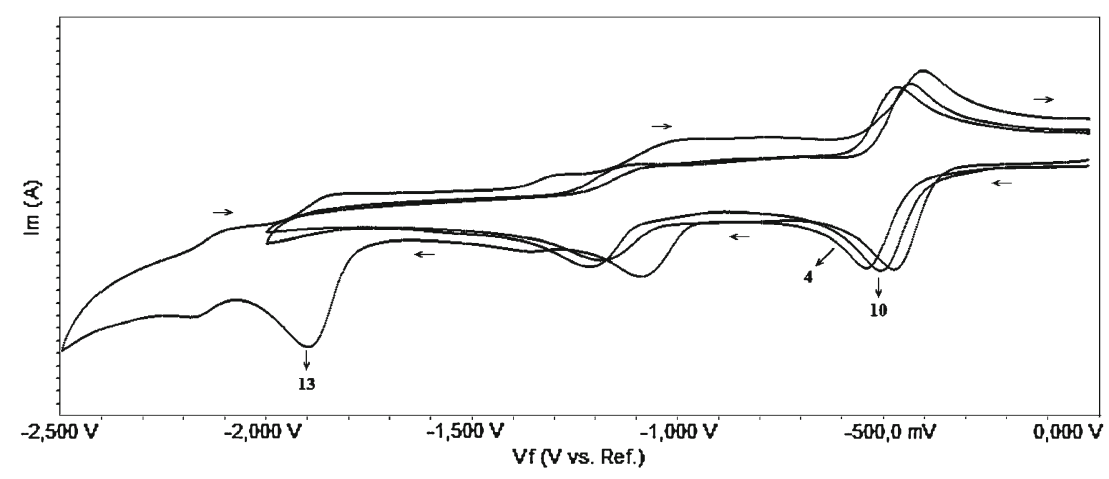

Figure 3. Cyclic voltammogram of compounds 4, 10 and 13 in DMF obtained by using tetrabutyl ammonium perchlorate $(0.1 \mathrm{M})$ as the supporting electrolyte at scan rate of $\mathrm{v}=0.1 \mathrm{~V} \mathrm{~s}^{-1}$.

15 showed behaviour typical of quinones in aprotic medium. ${ }^{29,30}$ Two reversible one-electron waves were observed. The first reversible reduction wave was, for 1, $-0.287 \mathrm{~V}$ vs. $\mathrm{Ag} / \mathrm{AgCl}$, represented the addition of one electron to the quinone core to form a semiquinone anion radical. Furthermore, if we consider that the ratio of the cathodic to anodic peak current was near 1 $\left(i_{\mathrm{pc}} / i_{\mathrm{pa}}=0.99\right.$ for compound $\left.\mathbf{1}\right)$, it could be proposed that 2,3-dichloro-1,4-naphthoquinone $\mathbf{1}$ is transformed to a stable semiquinone anion radical $\left(\mathrm{Q}^{-}\right)$. In the case of more negative reduction process (second cathodic and first anodic peak), the largest difference between the cathodic and anodic peak potential $\left(E_{\mathrm{pa}}-E_{\mathrm{pc}}=\right.$ $99.7 \mathrm{mV}$ ) (see in table 6) suggests that the reduction of the semiquinone anion radical $\left(\mathrm{Q}^{-}\right)$to the dianion $\left(\mathrm{Q}^{2-}\right)$ was partially controlled by the electronic transference and by diffusion. These oxidation-reduction reactions could be represented by the following equations: ${ }^{31}$

$$
\begin{gathered}
\mathrm{Q}+\mathrm{e}^{-} \rightleftharpoons \mathrm{Q}^{-}(\text {reversible }) \\
\mathrm{Q}^{--}+\mathrm{e}^{-} \rightleftharpoons \mathrm{Q}^{-2} \text { (quasi }- \text { reversible). }
\end{gathered}
$$

For this electrochemical reaction, the standard potential was also estimated from the difference between both the anodic and cathodic peak potential: $E_{1 / 2}=$ $-1.027 \mathrm{~V}$ (vs. SCE), ${ }^{31}$ in our study, $E_{1 / 2}=-1.024 \mathrm{~V}$ (vs. GCE) in table 6 for $\mathbf{1}$. The cyclic voltammogram of $p$-chloranil 15 exhibits an anodic peak related to the oxidation of $\mathrm{HQ}^{-}$, presents a cathodic peak related to reduction of $p$-chloranil $(\mathrm{Q})$ to reduced $p$-chloranil $\left(\mathrm{HQ}^{-}\right)$.

The reversibility of this redox couple $\left(I_{\mathrm{pc}} \approx I_{\mathrm{pa}}\right)$ suggests that the dianion was also stable in the time scale of the voltammetric experiments. The ratio of the cathodic to anodic peak current was near 1 for compounds $\mathbf{3}, \mathbf{4}$, $6,7,8,10,11,13,14,16$ and 17 . Two reduction waves representing in table 6 , were observed at a scan rate 0.1 $\mathrm{Vs}^{-1}$ for compounds $4,6,8,10,11,16$ and 17. The redox behaviour of compounds $3,7,13$ and 14 was very different. Three reduction waves were observed for $\mathbf{3}$ and 14, and four reduction waves were observed for 7 and 13. Cyclic voltammogram of compounds 4, 10 and 13 in DMF was given in figure 3. The intensity of the two quinone reduction waves has decreased, the quasireversible character of the second wave has almost disappeared for 3, 7, 13 and $\mathbf{1 4}$. The potentials for reductions were more negative for $3,4,6,7,8,10,11,13$ and $\mathbf{1 4}$ according to 2,3-dichloro-1,4-naphthoquinone $\mathbf{1}$.

\section{Conclusions}

The aim of this study was to synthesize and characterize some naphthoquinone and benzoquinone $\mathbf{3}, \mathbf{4}$, 6, 7, 8, 10, 11, 13, 14, 16 and 17 compounds. Their structures were determined by using micro analysis, FT-IR, ${ }^{1} \mathrm{H}-\mathrm{NMR},{ }^{13} \mathrm{C}-\mathrm{NMR}$, MS, UV-Vis. Photo- and electrochemical properties of $\mathrm{N}-$, S-, O-substituted naphthoquninone and S-, O-substituted benzoquinone compounds were investigated by using fluorescence spectroscopy and electrochemical method (cyclic voltammetry). The crystal structure of compound 13 was determined by X-ray diffraction method. These compounds possess high solubility in various organic solvents such as chloroform, dichloromethane, tetrahydrofurane and are insoluble in water.

\section{Acknowledgement}

We thank the Research Project Fund of Istanbul University for financial support to carry out this work. 


\section{References}

1. Kinoshita S, Koura Y, Kariya H, Ohsaki N and Watanabe T 1999 Pest. Sci. 55(6) 659

2. Scherbak N, Strid A and Eriksson L A 2005 Chem. Phys. Lett. 414243

3. Sutovsky Y, Likhtenshtein G I and Bittner S 2003 Tetrahedron $\mathbf{5 9} 2939$

4. Hasegawa T, Mochida T, Kondo R, Kagoshima K, Iwasa Y, Akutagawa T, Nakamura, T and Saito G 2000 Phys. Review B 6210059

5. Cormier R A, Posey M R, Bell W L and Fonda H N 1989 Tetrahedron 45(15) 4831

6. Chia V K F, Soriaga M P and Hubbard A T 1983 J. Phys. Chem. 87(2) 232

7. Slana G B C A, Azevedo M S, Lopes R S C, Lopes C C and Cardoso J N 2006 Beilst. J. Org. Chem. 21

8. Ibis C and Gunes Z O 2008 Dyes Pigments 77(1) 39

9. Wang W, Li T, Milburn R, Yates J, Hinnant E, Luzzio M J, Noble S A and Attardo G 1998 Bioorg. Med. Chem. Lett. 81579

10. Thines E, Anke H and Sterner O 1998 J. Nat. Prod. 61 306

11. Boudalis A K, Policand X, Sournia-Saquet A, Donnadieu B and Tuchaques J P 2008 Inorg. Chim. Acta 3611681

12. Behforouz M, Haddad J, Cai W and Gu Z 1998 J. Org. Chem. 63(2) 343

13. Fieser L F and Brown R H 1949 J. Am. Chem. Soc. 71 3609

14. Sayil C and Ibis C 2010 Russ. J. Org. Chem. 46(2) 209

15. Tandon V K and Maurya H K 2009 Hceterocycles 77(1) 611

16. Prescott B 1969 J. Med. Chem. 12181

17. Chen C, Liu Y Z, Shia K S and Tseng H Y 2002 Bioorg. Med. Chem. Lett. 12(19) 2729
18. Parr R W and Reiss J A 1984 Austr. J. Chem. 37(2) 389

19. Altomare A, Cascarano G, Giacovazzo C, Guagliardi A, Burla M, Polidori G and Camalli M 1994 J. Appl. Cryst. 27435

20. Watkin D J, Prout C K, Carruthers J R and Betteridge J R 1996 Crystals Issue 10, P W Chemical Crystallography Laboratory, Oxford, UK

21. Farrugia L J 1997 J. Appl. Cryst. 30565

22. Crystallographic data (excluding structure factors) for the structures in this paper have been deposited in the Cambridge Crystallographic Data Centre as supplementary publication number CCDC 724897 for $\mathbf{1 3}$. Copies of the data can be obtained, free of charge, via www.ccdc.cam.ac.uk/conts/retrieving.html or from the Cambridge Crystallographic Data Centre, CCDC, 12 Union Road, Cambridge CB2 1EZ, UK; fax: +44 1223 336033. E-mail: deposit@ccdc.cam.ac.uk.

23. Win T and Bittner S 2005 Tetrahedron Lett. 463229

24. Kuroda S, Oda M, Takamatsu H, Hatakeyama H, Noda C, Zhang Y, Miyatake R, Thanh N C, Yanagida A, Kyougoku M and Kawakami T 2007 Sci. Tec. Adv. Mater. 8306

25. Umadevi M, Ramasubbu A, Vanelle $\mathrm{P}$ and Ramakrishnan V 2003 J. Raman Spectrosc. 34112

26. Ibis C and Ayla S S 2008 Arkivoc 629

27. Ibis C and Deniz N G 2010 Phosporus Sulfur Silicon 1852324

28. Boudalis A K, Policand X, Sournia-Saquet A, Donnadieu B and Tuchagues J P 2008 Inorg. Chim. Acta 3611681

29. Ibis C, Ayla S S and Deniz N G 2010 Asian J. Chem. 22(8) 6195

30. Abreu F C, Lopes A O, Pereira M A, Simone C A and Goulart M O F 2002 Tetrahedron Lett. 438153

31. Gozales F J 1998 Electroanalysis 10(9) 638 